\title{
The Influence of Dental Hygiene Student's Communication Ability and Conflict Management Types on Adaptation to College Life
}

\author{
Myong-Suk Shin ${ }^{1}, \mathrm{Ji}-\mathrm{H}$ young $\mathrm{Han}^{2}$, and Ji-Min Hwang ${ }^{3, \dagger}$ \\ 'Department of Dental Hygiene, Dongnam Health University, Suwon 16328, ${ }^{2}$ Department of Dental Hygiene, \\ Suwon Science College, Hwaseong 18516, ${ }^{3}$ Department of Dental Hygiene, Baekseok Culture University, \\ Cheonan 31065, Korea
}

\begin{abstract}
Background: The purpose of this study was to investigate the effects of dental hygiene students' communication ability and conflict management types on adaptation to college life improve adaptation to college life and to suggest strategies to play a role as a professional dental hygienist in clinical practice.

Methods: The subjects of this study were selected by random sample extraction of dental hygiene students from two colleges in Gyeonggi and one Chungcheong area. The survey was conducted online for dental hygiene students from July 20 to October 31 , 2020. In order to comply with research ethics, this study was investigated with the consent of the subjects. The sample was analyzed for the final 351.

Results: Dental hygiene students' communication ability was 3.74 points, conflict management types was 3.01 points, and adaptation to college life was 3.30 points. In the type of conflict management according to the general characteristics, the problem-solving method, the avoidance method, the compromise method, and the concession method showed statistically significant differences in major satisfaction. Among the types of conflict management, the highest positive correlation ( $r=0.613)$ was shown in the relationship between the problem-solving method and the compromise method. Factors influencing the adaptation to college life were concentration, forced method, self-disclosure, conversational coherence, and social relaxation. Conclusion: This study is significant in that it derives sub-areas of communication ability and conflict management types that influence adaptation to college life. In the future, there is a need to improve the quality of dental hygienists by continuously conducting research on the types of conflict management targeting dental hygienists, and responding more proactively and actively to conflict situations in the clinical field.
\end{abstract}

Key Words: Adaptation, College life, Communication, Conflict, Dental hygiene, Management

\section{Introduction}

College students are a period of adapting to various changes and environments and forming a sense of identity and values. College life and academic adaptation are very important for a successful college life and for the vision of life in the future. Adaptation to college life is not only about academic achievement, but also responding to new and diverse experiences such as interpersonal relationships and coping with the demands of college life ${ }^{1,2)}$.

In particular, dental hygiene students should continue to communicate and cooperate with patients, guardians, and colleagues in the clinical field in the future. Therefore, in order to perform the overall role of dental treatment, it is necessary to have problem solving ability, judgment ability, and communication ability ${ }^{3)}$. Dental hygiene students are experiencing many conflicts and difficulties during clinical practice due to insufficient communication ability 
and interpersonal skills. It is reported that this decreases satisfaction with clinical practice and leads to skepticism about the career path ${ }^{4,5)}$. Eventually, it has a negative effect on the adaptation of college life, which leads to dropouts such as leave of absence or withdrawal ${ }^{6}$. In this way, adaptation to college life affects your future career and your life as a whole.

Recently, as the subject of health care services has changed to focus on subjects, the importance of communication capability in the clinical scene has been emphasized ${ }^{7}$. This communication ability can be sufficiently improved through education because it is acquired not by innate ability. Therefore, it is necessary to materialize it through education ${ }^{8)}$.

In addition, as long as humans live in a group, conflicts between individuals and groups are inevitable, and there are inevitable conflicts in various forms ${ }^{9}$. For college students to engage in social activities after graduation, it is important to experience various group activities, deal with intra-group conflicts, and grow through them ${ }^{10)}$. In particular, hospitals are made up of a variety of occupations, so job conflicts are relatively high compared to other general organizations ${ }^{11)}$. So it is more important to dental hygiene students.

In previous studies, there are various factors that influence conflict, but many studies consistently suggest a high correlation between communication and conflict $^{12}$. People with excellent communication abilities have been reported to efficiently resolve conflicts with others, achieve high academic achievement, improve self-esteem, and have high potential for employment and promotion ${ }^{13)}$.

The adaptation to college life of college students was higher with better interpersonal relationships, higher levels of personality behavior ${ }^{14)}$, and higher major satisfaction levels and academic achievements ${ }^{15)}$. College students' adaptation to college life was found to be higher with better interpersonal relationships and higher levels of personality behavioral areas ${ }^{16}$. While many other factors are related to adaptation to college life, research on the effects of communication ability and conflict management types on college life adaptation is insufficient. Dental hygienists working in clinical settings will become experts in professional competency if they manage conflict management and communication skills from college.

The purpose of this study is to understand the impact on adaptation to college life according to dental hygiene and student communication ability and conflict management types. Through this, it was intended to suggest a strategy to improve adaptation to college life as well as to play a role as a professional dental hygienist in clinical practice.

\section{Materials and Methods}

\section{Subjects}

The data of this study were selected by random sample extraction of dental hygiene departments of two colleges in Gyeonggi and one college in Chungcheong. The survey was conducted on first, second, and third graders at each college, and the survey period was from July 20 to October 31, 2020. This study was investigated with the consent of the subject in order to comply with the research ethics. The sample size was used in the G Power 3.1 program, and 351 people were calculated for correlation and regression analysis based on effect size 0.30 and significance level 0.05 , and statistical power 0.95 . No questionnaires were excluded, and samples were analyzed for the final 351 subjects.

\section{Variables used in the analysis}

The general characteristics were age, sex, grade, religion, economic level, residence, major satisfaction, and college life satisfaction. In terms of major satisfaction and college life satisfaction, 5 points were very satisfied, and 1 point was very dissatisfied.

As a variable for communication ability, the GICC (Global Interpersonal Communication Competence Scale) item developed by $\mathrm{Hur}^{17)}$ was used. The questions are self-disclosure (3 questions), empathy ( 3 questions), social relaxation (3 questions), assertiveness (3 questions), concentration (3 questions), interaction management (3 questions), expressiveness (3 questions), supportiveness (3 questions), immediacy (3 questions), efficiency (3 questions), social appropriateness (3 questions), conversational coherence (3 questions), goal detection (3 questions), responsiveness (3 questions), noise control (3 questions), 15 sub-areas and a total of 45 questions. The Likert-type 
5-point scale with a perfect score of 5 was used, and the Cronbach's $\alpha$ value was 0.913 .

For the type of conflict management, Kilmann and Thomas's research tool was used (1975) ${ }^{18)}$. The questionnaire consisted of a problem solving method (5 questions), a forced method (5 questions), an avoidance method (5 questions), a compromise method (5 questions), a concession method (5 questions), and a total of 25 questions. Each question was surveyed on a 5-point scale by assigning 'very much' to 5 points and 'not at all' as 1 point, and the Cronbach's $\alpha$ value of the research tool was 0.714 .

Adaptation to college life used Kwon's questionnaire ${ }^{19)}$. There are four questions for academic adaptation, five questions for social adaptation, five questions personalemotional adaptation, and five questions for college environment adaptation, with a total of 19 questions. The Likert-type 5-point scale with a perfect score of 5 was used, and the Cronbach's $\alpha$ value was 0.869 .

\section{Data analysis}

Data were analyzed using statistical analysis software PASW Statistics 18.0 (IBM Co., Armonk, NY, USA). The general characteristics were frequency analysis, and the communication ability, conflict management types, and adaptation to college life were analyzed with descriptive statistics. T-test and one-way ANOVA analysis were performed to compare communication ability, conflict management types, and adaptation to college life according to general characteristics. An equal variance test was performed using the Levene statistic, and differences between groups were analyzed through the Scheffe post-test. Pearson's correlation analysis was performed to see the correlation between communication ability, conflict management types, and adaptation to college life. Multiple regression analysis was performed to find out the effect on adaptation to college life and the significance level of all analyzes was set to 0.05 .

\section{Results}

\section{Communication ability, conflict management types, and adaptation to college life}

In terms of communication ability, responsiveness was the highest with 4.26, followed by concentration with 4.17. Assertiveness and conversational coherence were the lowest at 3.40. As for the type of conflict management, the compromise method was the highest with 3.73 , and the forced method was the lowest with 1.93. Among adaptation to college life, college environment adaptations were the highest at 3.45. The academic adaptation was the lowest at 3.03 (Table 1).

\section{Differences in conflict management types according to general characteristics}

The comparison of five types of conflict management according to general characteristics is as follows. Among the general characteristics, the higher the grade, the higher the forced method $(\mathrm{p}=0.003)$ and the avoidance method $(p=0.046)$, showing a statistically significant difference.

Table 1. Communication Ability, Conflict Management Types, Adaptation to College Life

\begin{tabular}{lc}
\hline \multicolumn{1}{c}{ Variable } & $\begin{array}{c}\text { Mean } \pm \text { standard } \\
\text { deviation }\end{array}$ \\
\hline Communication ability & $3.74 \pm 0.401$ \\
Self-disclosure & $3.53 \pm 0.679$ \\
Empathy & $3.87 \pm 0.552$ \\
Social relaxation & $3.51 \pm 0.496$ \\
Assertiveness & $3.40 \pm 0.748$ \\
Concentration & $4.17 \pm 0.616$ \\
Interaction management & $3.63 \pm 0.580$ \\
Expressiveness & $3.63 \pm 0.672$ \\
Supportiveness & $3.46 \pm 0.564$ \\
Immediacy & $3.90 \pm 0.661$ \\
Efficiency & $3.78 \pm 0.648$ \\
Social appropriateness & $4.13 \pm 0.595$ \\
Conversational coherence & $3.40 \pm 0.715$ \\
Goal detection & $3.76 \pm 0.630$ \\
Responsiveness & $4.26 \pm 0.621$ \\
Noise control & $3.70 \pm 0.555$ \\
Conflict management types & $3.01 \pm 0.312$ \\
Problem solving method & $3.53 \pm 0.509$ \\
Forced method & $1.93 \pm 0.652$ \\
Avoidance method & $2.41 \pm 0.682$ \\
Compromise method & $3.73 \pm 0.554$ \\
Concession method & $3.47 \pm 0.554$ \\
Adaptation to college life & $3.30 \pm 0.595$ \\
Academic adaptation & $3.03 \pm 0.784$ \\
Social adaptation & $3.22 \pm 0.696$ \\
Personal-emotional adaptation & $3.44 \pm 0.894$ \\
College environment adaptation & $3.45 \pm 0.659$ \\
\hline
\end{tabular}




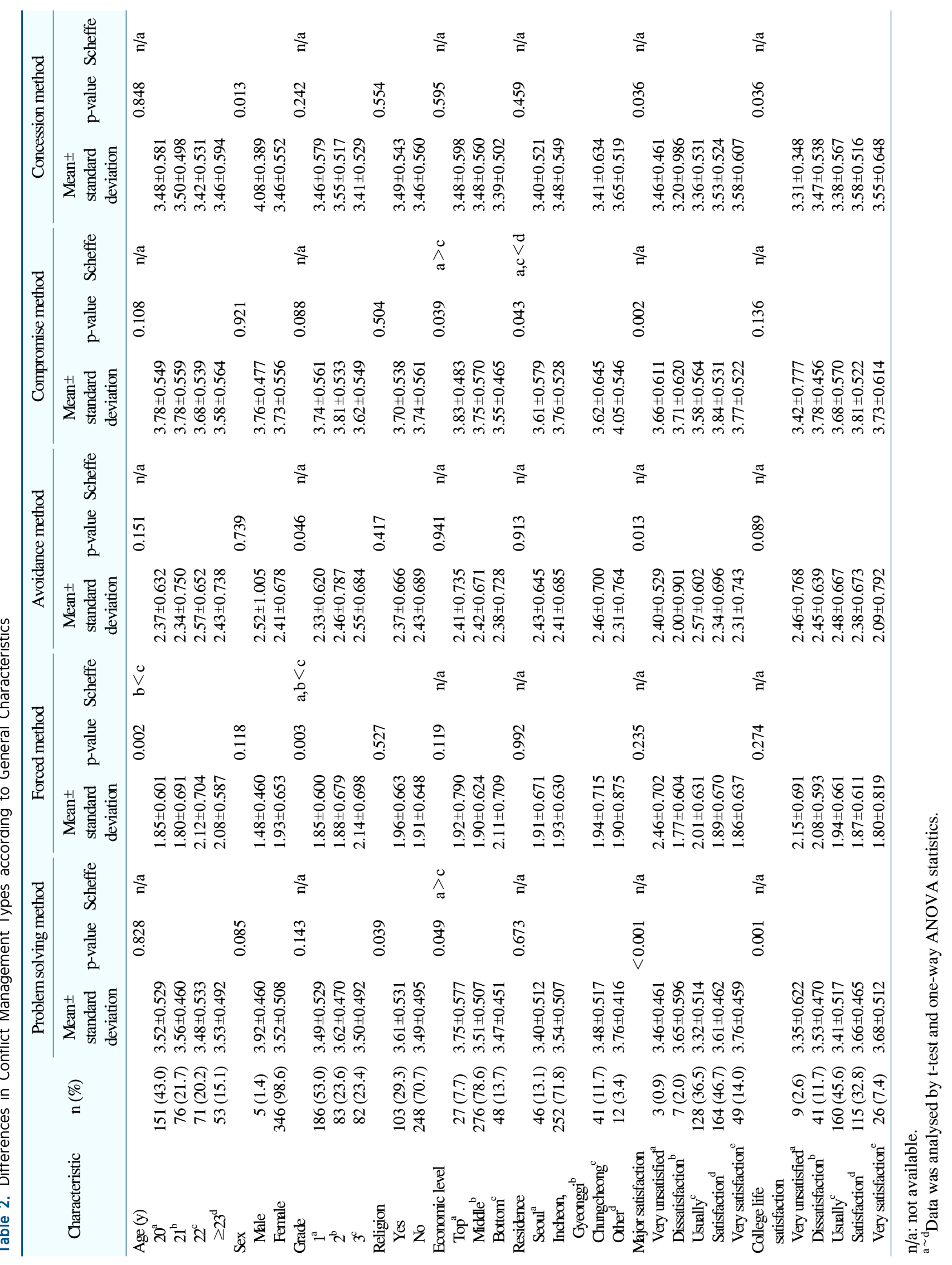


The higher the economic level, the higher the problem solving method $(\mathrm{p}=0.049)$ and the compromise method $(\mathrm{p}=0.039)$. The problem-solving method $(\mathrm{p}<0.001)$, the avoidance method $(\mathrm{p}=0.013)$, the compromise method $(\mathrm{p}=0.002)$, and the concession method $(\mathrm{p}=0.036)$ showed statistically significant differences according to major satisfaction. The problem-solving method $(\mathrm{p}=0.001)$ and the concession method $(p=0.036)$ showed significant differences according to the degree of satisfaction with college life (Table 2).

\section{Differences in communication ability and adaptation to college life according to general characteristics}

Among the general characteristics, there was a statistically significant difference in adaptation to college life according to age and grade $(p=0.011, p=0.031)$. There were statistically significant differences in communication ability and adaptation to college life according to economic level, major satisfaction, and college life satisfaction. The higher the economic level, the higher the communication ability $(\mathrm{p}=0.012)$ and adaptation to college life $(\mathrm{p}<0.001)$. The higher the degree of satisfaction with college life, the higher the degree of adaptation to college life $(\mathrm{p}<0.001$, Table 3$)$.

Table 3. Differences in Communication Ability and Adaptation to College Life according to General Characteristics

\begin{tabular}{|c|c|c|c|c|c|c|c|c|}
\hline \multirow[b]{2}{*}{ Characteristic } & \multirow[b]{2}{*}{ Category } & \multirow[b]{2}{*}{$\mathrm{n}(\%)$} & \multicolumn{3}{|c|}{ Communication ability } & \multicolumn{3}{|c|}{ Adaptation to college life } \\
\hline & & & $\begin{array}{c}\text { Mean } \pm \\
\text { standard } \\
\text { deviation }\end{array}$ & p-value & Scheffe & $\begin{array}{c}\text { Mean } \pm \\
\text { standard } \\
\text { deviation }\end{array}$ & p-value & Scheffe \\
\hline \multirow[t]{4}{*}{ Age (y) } & $20^{\mathrm{a}}$ & $151(43.0)$ & $3.76 \pm 0.411$ & 0.365 & $\mathrm{n} / \mathrm{a}$ & $3.27 \pm 0.588$ & 0.011 & $b>d$ \\
\hline & $21^{\mathrm{b}}$ & $76(21.7)$ & $3.79 \pm 0.363$ & & & $3.49 \pm 0.585$ & & \\
\hline & $22^{\mathrm{c}}$ & $71(20.2)$ & $3.71 \pm 0.449$ & & & $3.25 \pm 0.540$ & & \\
\hline & $23 \leq^{d}$ & $53(15.1)$ & $3.67 \pm 0.356$ & & & $3.17 \pm 0.653$ & & \\
\hline \multirow[t]{2}{*}{ Sex } & Male & $5(1.4)$ & $3.67 \pm 0.089$ & 0.134 & & $3.30 \pm 0.691$ & 0.990 & \\
\hline & Female & $346(98.6)$ & $3.74 \pm 0.404$ & & & $3.30 \pm 0.595$ & & \\
\hline \multirow[t]{3}{*}{ Grade } & $1^{\mathrm{a}}$ & $186(53.0)$ & $3.76 \pm 0.406$ & 0.689 & $\mathrm{n} / \mathrm{a}$ & $3.27 \pm 0.601$ & 0.031 & $\mathrm{~b}>\mathrm{c}$ \\
\hline & $2^{\mathrm{b}}$ & $83(23.6)$ & $3.72 \pm 0.364$ & & & $3.44 \pm 0.557$ & & \\
\hline & $3^{c}$ & $82(23.4)$ & $3.72 \pm 0.429$ & & & $3.21 \pm 0.602$ & & \\
\hline \multirow[t]{2}{*}{ Religion } & Yes & $103(29.3)$ & $3.78 \pm 0.438$ & 0.209 & & $3.37 \pm 0.621$ & 0.147 & \\
\hline & No & $248(70.7)$ & $3.73 \pm 0.385$ & & & $3.27 \pm 0.583$ & & \\
\hline \multirow[t]{3}{*}{ Economic level } & Top $^{a}$ & $27(7.7)$ & $3.92 \pm 0.399$ & 0.012 & $a>c$ & $3.50 \pm 0.686$ & $<0.001$ & $a, b>c$ \\
\hline & Middle $^{\mathrm{b}}$ & $276(78.6)$ & $3.74 \pm 0.395$ & & & $3.33 \pm 0.578$ & & \\
\hline & Bottom $^{c}$ & $48(13.7)$ & $3.64 \pm 0.413$ & & & $3.00 \pm 0.551$ & & \\
\hline \multirow[t]{4}{*}{ Residence } & Seoul $^{\mathrm{a}}$ & $46(13.1)$ & $3.66 \pm 0.415$ & 0.392 & $\mathrm{n} / \mathrm{a}$ & $3.24 \pm 0.559$ & 0.448 & $\mathrm{n} / \mathrm{a}$ \\
\hline & Incheon, Gyeonggi ${ }^{\mathrm{b}}$ & $252(71.8)$ & $3.75 \pm 0.399$ & & & $3.29 \pm 0.613$ & & \\
\hline & Chungcheong $^{\mathrm{c}}$ & $41(11.7)$ & $3.78 \pm 0.389$ & & & $3.36 \pm 0.552$ & & \\
\hline & Other $^{\mathrm{d}}$ & $12(3.4)$ & $3.82 \pm 0.447$ & & & $3.52 \pm 0.493$ & & \\
\hline \multirow[t]{5}{*}{ Major satisfaction } & Very unsatisfied $^{\mathrm{a}}$ & $3(0.9)$ & $3.88 \pm 0.276$ & $<0.001$ & $\mathrm{n} / \mathrm{a}$ & $3.03 \pm 0.425$ & $<0.001$ & $\mathrm{~b}<\mathrm{e}$ \\
\hline & Dissatisfaction $^{\mathrm{b}}$ & $7(2.0)$ & $3.98 \pm 0.405$ & & & $2.77 \pm 0.643$ & & \\
\hline & Usually $^{c}$ & $128(36.5)$ & $3.57 \pm 0.389$ & & & $3.01 \pm 0.489$ & & \\
\hline & Satisfaction $^{\mathrm{d}}$ & $164(46.7)$ & $3.81 \pm 0.376$ & & & $3.42 \pm 0.556$ & & \\
\hline & Very satisfaction $^{\mathrm{e}}$ & $49(14.0)$ & $3.92 \pm 0.370$ & & & $3.74 \pm 0.568$ & & \\
\hline \multirow[t]{5}{*}{ College life satisfaction } & Very unsatisfied $^{\mathrm{a}}$ & $9(2.6)$ & $3.89 \pm 0.437$ & $<0.001$ & $\mathrm{n} / \mathrm{a}$ & $2.71 \pm 0.521$ & $<0.001$ & $\mathrm{a}<\mathrm{c}<\mathrm{d}<\mathrm{e}$ \\
\hline & Dissatisfaction $^{\mathrm{b}}$ & $41(11.7)$ & $3.65 \pm 0.460$ & & & $2.78 \pm 0.519$ & & \\
\hline & Usually $^{c}$ & $160(45.6)$ & $3.64 \pm 0.374$ & & & $3.18 \pm 0.452$ & & \\
\hline & Satisfaction $^{\mathrm{d}}$ & $115(32.8)$ & $3.85 \pm 0.377$ & & & $3.53 \pm 0.572$ & & \\
\hline & Very satisfaction $^{\mathrm{e}}$ & $26(7.4)$ & $3.94 \pm 0.377$ & & & $4.01 \pm 0.450$ & & \\
\hline
\end{tabular}

n/a: not available.

${ }^{\mathrm{a} \sim \mathrm{d}}$ Data was analysed by t-test and one-way ANOVA statistics. 


\section{Correlation between communication ability and conflict management types and adaptation to college life}

Among the types of conflict management, the relationship between problem solving method and compromise showed the highest positive correlation ( $r=0.613)$. Among the types of communication ability and conflict management, the forced method showed the lowest negative correlation $(r=-0.356$, Table 4).

\section{Factors affecting adaptation to college life}

Prior to regression analysis, the result of analysis to diagnose multicollinearity between independent variables was $0.58 \sim 0.92$, which was more than 0.1 . Variance expansion coefficient was 1.0 to 1.7 , which did not exceed 10 , indicating that there was no problem in multicollinearity between independent variables. In order to determine the relative influence of which factors affect the adaptation to college life, we compared them through the $\beta$ value of the standardization coefficient. Concentration 0.166 , forced method -0.240 , self-disclosure 0.186 , conversational coherence 0.145 , social relaxation -0.104 , showing that self-disclosure has the highest static relationship and has the highest impact on adaptation to college life. The explanatory power was $22.0 \%$ and the Durbin-Watson index was 1.830 , which was close to 2 , indicating that there was no autocorrelation in the error term. The regression model was found to be statistically significant $(\mathrm{F}=20.720, \mathrm{p}<0.001$, Table 5).

\section{Discussion}

This study was investigated to find ways to improve effective conflict management and communication ability by finding out the relationship between adaptation to college life by identifying communication ability and

Table 4. Correlation between Communication Ability and Conflict Management Types and Adaptation to College Life

\begin{tabular}{|c|c|c|c|c|c|c|c|}
\hline Variable & $\begin{array}{l}\text { Communication } \\
\text { ability }\end{array}$ & $\begin{array}{l}\text { Problem } \\
\text { solving } \\
\text { method }\end{array}$ & $\begin{array}{l}\text { Forced } \\
\text { method }\end{array}$ & $\begin{array}{l}\text { Avoidance } \\
\text { method }\end{array}$ & $\begin{array}{c}\text { Compromise } \\
\text { method }\end{array}$ & $\begin{array}{c}\text { Concession } \\
\text { method }\end{array}$ & $\begin{array}{c}\text { Adaptation } \\
\text { to college } \\
\text { life }\end{array}$ \\
\hline Communication ability & 1 & & & & & & \\
\hline Problem solving method & $0.575 * * *$ & 1 & & & & & \\
\hline Forced method & $-0.356 * * *$ & $-0.212 * * *$ & 1 & & & & \\
\hline Avoidance method & $-0.350 * * *$ & $-0.126^{*}$ & $0.506^{* * *}$ & 1 & & & \\
\hline Compromise method & $0.501 * * *$ & $0.613 * * *$ & $-0.318 * * *$ & $-0.202 * * *$ & 1 & & \\
\hline Concession method & $0.285^{* * *}$ & $0.530 * * *$ & $-0.205^{* * *}$ & 0.022 & $0.527 * * *$ & 1 & \\
\hline Adaptation to college life & $0.379 * * *$ & $0.231 * * *$ & $-0.338 * * *$ & $-0.296 * * *$ & $0.204 * * *$ & 0.049 & 1 \\
\hline
\end{tabular}

Data was analysed by Pearson correlation statistics.

${ }^{*} \mathrm{p}<0.05, * * * \mathrm{p}<0.001$.

Table 5. Factors Affecting Adaptation to College Life

\begin{tabular}{|c|c|c|c|c|c|c|}
\hline Variable & $\mathrm{B}$ & SE & $\beta$ & $\mathrm{t}(\mathrm{p})$ & TOL & VIF \\
\hline (Constant) & 2.503 & 0.319 & & $7.849 * * *$ & & \\
\hline Concentration & 0.161 & 0.060 & 0.166 & $2.699 * *$ & 0.586 & 1.705 \\
\hline Forced method & -0.219 & 0.050 & -0.240 & $-4.368^{* * *}$ & 0.739 & 1.354 \\
\hline Self-disclosure & 0.163 & 0.045 & 0.186 & $3.665^{* * *}$ & 0.861 & 1.161 \\
\hline Conversational coherence & 0.121 & 0.045 & 0.145 & $2.709 * *$ & 0.775 & 1.290 \\
\hline Social relaxation & -0.125 & 0.059 & -0.104 & $-2.117^{*}$ & 0.927 & 1.079 \\
\hline $\mathrm{F}(\mathrm{p})$ & \multicolumn{6}{|c|}{$20.720 * * *$} \\
\hline Adjusted $\mathrm{R}^{2}$ & \multicolumn{6}{|c|}{0.220} \\
\hline Durbin-Watson & \multicolumn{6}{|c|}{1.830} \\
\hline
\end{tabular}

TOL: tolerance, VIF: variance expansion coefficient.

${ }^{*} \mathrm{p}<0.05,{ }^{* *} \mathrm{p}<0.01,{ }^{* * *} \mathrm{p}<0.001$. 
conflict management types with dental hygiene students.

As a result of the study, the average score of the dental hygiene and communication ability of students was 3.74 out of 5 points. This result was higher than that of the study of dental hygiene students $(3.28)^{3)}$ and the study of nursing college students $(3.51)^{16)}$. Among the sub-areas, responsiveness and concentration were the highest, which was consistent with the study of nursing students ${ }^{16)}$. After employment, dental hygiene students communicate a lot with colleagues and patients in the clinical field. It is very encouraging to have high responsiveness and concentration to the other person. Among the sub-areas of communication ability, conversational coherence is the ability to interconnect opinions generated in the process of conversation in a meaningful and orderly manner ${ }^{17)}$. The lowest score was 3.39. As a result of this, it seems that the subject of the study is a college student, and thus, there is still insufficient self-assertion and coping with professionalism in the job or environmental change.

The conflict management types score of the study subjects was 3.01 points, and among the sub-areas, the compromise method was the highest with 3.74 points. Dental hygiene students who are exposed to in-school practice and clinical practice seem to prefer the strategy of compromise $^{20)}$ so that each party can be satisfied to some extent. Among the dental hygiene students' major satisfaction, among the conflict management types, problem solving methods, avoidance methods, compromise methods, and concession methods were related to the problem solving methods, avoidance methods, compromise methods, and concession methods. It seems that most of the students who are satisfied with their major actively cope with conflict management and are positively adapting to college life. In addition, since graduation is exposed to more conflict than college life in complex and diverse clinical environments, conflict management is very important even for dental hygienists in clinical practice $^{21)}$.

The average of the study subjects' adaptation to college life was 3.30 points. Among the sub-areas, college environment adaptation was high with 3.45 points and personal-emotional adaptation with 3.44 points, and academic adaptation was the lowest with 3.03 points. As a result of the lowest academic adaptation, dental hygiene students seem to have difficulty in adaptation to college life due to the heavy pressure on academics, clinical practice, and national examinations. In addition, it was found that the economic level, major satisfaction, and college life satisfaction of dental hygiene students affected not only their communication ability but also their adaptation to college life. $\mathrm{Yi}$ and $\mathrm{Kwak}^{22)}$ reported that students with high satisfaction with their major and high academic grades showed a positive tendency toward their major and college, and that their sense of goals for careers was clear, which could improve adaptation to college life.

In terms of communication ability, conflict management type, and adaptation to college life, dental hygiene and students showed a high positive correlation in problem solving method and compromise method among conflict management types. It seems that the better the ability to respond logically to the situation when a problem occurs in college life, the better the conflict can be resolved by drawing a reasonable alternative with the other party.

The factors affecting the adaptation to college life of dental hygiene students were as follows. Concentration to pay attention to signals from the other party, selfdisclosure that expands the breadth of trust and understanding in the other person to form a stronger human relationship, conversational coherence, which is the ability to coherently communicate one's opinion to the other person. Social relaxation ${ }^{17)}$, the ability to accept criticism, influenced the adaptation to college life of dental hygiene students. If communication ability is insufficient, it is not delivered as intended, resulting in conflict with the other party ${ }^{16)}$. It is related to the clinical field and college life after graduation. Therefore, dental hygiene students will need a variety of educational strategies such as simulations and situational plays through comparison and activities.

Among conflict management types, the forced method was found to have an effect on adaptation to college life. The forced method is a method that pushes one's position to fulfill its position ${ }^{20)}$. This is a type that has a tendency to be uncertain about the opportunity to achieve one's goals, and shows a negative correlation to adaptation to college life, which should be avoided.

The limitation of this study is that it is difficult to 
generalize because it was conducted for some local dental hygiene and students. In addition, objective comparison was difficult due to lack of research on dental hygiene on conflict management types. However, it is significant in that it derives sub-areas of communication ability and conflict management types that affect adaptation to college life. In the future, research on conflict management types for dental hygienists should be conducted so that dental hygienists have the ability to actively and actively cope with conflict situations.

\section{Notes}

\section{Conflict of interest}

No potential conflict of interest relevant to this article was reported.

\section{Ethical approval}

This study was approved by the Institutional Review Board of Baekseok Culture University (No.2-7008132A-N-01).

\section{Author contributions}

Conceptualization: Myong-Suk Shin, Ji-Hyoung Han, and Ji-Min Hwang. Data acquisition: Myong-Suk Shin, Ji-Hyoung Han, and Ji-Min Hwang. Formal analysis: Ji-Min Hwang. Supervision: Myong-Suk Shin. Writingoriginal draft: Myong-Suk Shin and Ji-Min Hwang. Writing - review \& editing: Ji-Hyoung Han and Ji-Min Hwang.

\section{ORCID}

Myong-Suk Shin, https://orcid.org/0000-0002-2820-4772

Ji-Hyoung Han, https://orcid.org/0000-0003-1613-2879

Ji-Min Hwang, https://orcid.org/0000-0003-2199-8319

\section{References}

1. Choi HJ, Lee E: Mediation effects of self-efficacy between academic stress and college adjustment in first year nursing students. J Korean Acad Fundam Nurs 19: 261-268, 2012. https://doi.org/10.7739/jkafn.2012.19.2.261

2. Ye KH, Kim SJ: Study of adjustment to university life and department adaptation depended on gender in Dept. of Optometry. Korean J Vis Sci 16: 433-444, 2014.

3. Kim SJ, Kim HH: Impact of communication competence and empathy abilities on interpersonal relationship abilities among dental hygiene students. J Dent Hyg Sci 13: 304-313, 2013.

4. Jeong GS, Kim KA, Seong JA: The effect of learning style and critical thinking disposition on communication skill in nursing students. J Korean Acad Soc Nurs Educ 19: 413-422, 2013.

https://doi.org/10.5977/jkasne.2013.19.3.413

5. Lim SA: Communication ability according to self-awareness and other-awareness in some dental hygiene students. J Korean Soc Dent Hyg 16: 733-740, 2016. https://doi.org/10.13065/jksdh.2016.16.05.733

6. Magnussen L, Amundson M: Undergraduate nursing student experience. Nurs Health Sci 5: 261-267, 2003. https://doi.org/10.1046/j.1442-2018.2003.00158.x

7. Han MH, Lee KH: Effects of communication ability enhancement program for nursing students in Korea: a systematic review and meta-analysis. J Korean Acad Soc Nurs Educ 23: 15-26, 2017. https://doi.org/10.5977/jkasne.2017.23.1.15

8. Jang HS: The differences of the college student' stress coping strategies according to the family communication pattern and social-communication style. Soc Sci Res 26: 1-19, 2010.

9. Chun DY: Conflict management strategy and negotiation strategy. Sunhaksa, Seoul, pp.30-33, 2005.

10. Lee JH, Lee US, Lim SH: A study on the influence of individual characteristics of college students on the improvement of basic skills. IPR 2: 101-106, 2017. https://doi.org/10.21186/IPR.2017.2.1.101

11. Sung MH, Yoon HO, Lee HJ: A study on relationship between job stress, burnout experience and job satisfaction of nurses. Korean J Occup Health Nurs 16: 147-157, 2007.

12. Kwon SB, Lee HK, Ahn HY, Kim SY: Communication within hospital organizations and its impact on organizational conflict and organizational performance. Korean J Health Serv Manag 14: 79-91, 2020. https://doi.org/10.12811/kshsm.2020.14.1.079

13. Lee NH, Yoo SY: Influence of communication styles and stress coping on college adaptation in nursing students. Korean Parent Child Health J 20: 58-66, 2017. 
14. Jun MJ, Noh EK: The convergence study effected of adjustment to college life in character, interpersonal relationship of health-related college. JKCS 9: 433-442, 2018. https://doi.org/10.15207/JKCS.2018.9.4.433

15. Oh YJ: Predictors of college life adjustment among nursing students. JDC 15: 307-317, 2017. https://doi.org/10.14400/JDC.2017.15.7.307

16. Hwang SK, Lee YJ: Interpersonal communication competence and social anxiety in nursing students. J Korean Acad Soc Nurs Educ 21: 518-527, 2015. https://doi.org/10.5977/jkasne.2015.21.4.518

17. Hur GH: Construction and validation of a global interpersonal communication competence scale. KJJCS 47: 380-408, 2003.

18. Kilmann RH, Thomas KM: Interpersonal conflict-handling behavior as reflections of Jungian personality dimensions. Psychol Rep 37: 971-980, 1975. https://doi.org/10.2466/pr0.1975.37.3.971

19. Kwon EJ: The confirmation of five factor personality structure model and its relation to college adaptation according to sex. Unpublished doctoral dissertation, Sookmyung Women's University, Seoul, 2016.

20. Lee IS, Kim CH: Conflict management style, communication competence, and collaboration among hospital nurses and physicians. Korean J Rehabil Nurs 20: 69-78, 2017. https://doi.org/10.7587/kjrehn.2017.69

21. Namgung EJ, Kim EJ, Lee IH: Effects of self-consciousness and narcissism on conflict management style among college student. JFR 13: 1-25, 2009.

22. YI JE, Kwak HW: Relation of interpersonal relationship harmony, stress coping and adjustment to college life among nursing students. JDC 14: 527-537, 2016. https://doi.org/10.14400/JDC.2016.14.11.527 